\title{
Towards a Modular Language Curriculum for Using Tasks
}

\begin{abstract}
Task-based language teaching (TBLT) and task-supported language teaching (TSLT) are often seen as incompatible as they draw on different theories of language learning and language teaching. The position adopted in this paper, however, is that both approaches are needed especially in instructional contexts where 'pure' task-based teaching may be problematic for various reasons. The paper makes a case for a modular curriculum consisting of separate (i.e. nonintegrated) task-based and structure-based components. Different curriculum models are considered in the light of what is known about how a second language is learned. The model that is proposed assumes the importance of developing fluency first. It consists of a primary task-based module implemented with focuson-form (Long, 1991) and, once a basic fluency has been achieved, supported by a secondary structural module to provide for explicit accuracy-oriented work to counteract learned selective attention (N. Ellis, 2006) - one of the main sources of persistent error. The paper also addresses the content and grading of the taskbased and structural modules. It considers the factors that need to be considered in the vertical and horizontal grading of tasks but also points out that, for the time being, syllabus designers will have to draw on their experience and intuition as much as on research to make decisions about how to sequence tasks. An argument is presented for treating the structural component as a checklist rather than as a syllabus so as to allow teachers to address selectively those features that are found to be problematic for their students when they perform tasks.
\end{abstract}

\section{Introduction: Two kinds of syllabus}

In the 1970s, the traditional structural syllabus, consisting typically of an inventory of grammatical items, was challenged by new models of language (Hymes, 1971; Halliday, 1973), resulting in proposals for a communicative syllabus based on a functional view of language. The notional syllabus proposed by Wilkins (1976) drew heavily on these models of language. It listed semantic and functional categories - such as possibility and requesting - 
along with the linguistic means for realising these in language use. Such a syllabus was deemed 'analytic' in the sense that it required the learner to induce the elements comprising the linguistic system from the holistic input provided. In this respect it was viewed as fundamentally different from the 'synthetic' structural syllabus, where linguistic (typically grammatical) elements are taught, leaving it to the learner to assemble them in order to communicate.

In a sense, however, the structural and notional syllabuses were not so different. They were both examples of what White (1988) called a Type A syllabus. That is, they both focused on what is to be learned - the grammatical features in the case of the structural syllabus and the linguistic exponents of notions and functions in the notional syllabus. Both were interventionist and other-directed; that is they sought to plot the course of learning for the learner. White argued that Type B syllabuses are fundamentally different in that they focus on how language is to be learned, are non-interventionist and involve no pre-selection of the elements to be learned. A Type B syllabus assumes that learners have their own internal syllabus and should be left to follow this without any attempt to impose a sequence of learning externally. Consequently, the content of a Type B syllabus is not framed in language terms but rather in terms of either subject matter as in immersion programmes and content-based language teaching or as 'tasks' in task-based language teaching.

Brumfit (1984) made a similar distinction to White's. He distinguished a productbased syllabus consisting of explicitly stated linguistic content catering to an 'accuracy' approach to teaching where the primary focus is on language-as-usage and a process-based syllabus consisting of subject content and/or problem-solving activities catering to a 'fluency' approach where the focus is on the use of language for meaning-making. This distinction between an 'accuracy' and 'fluency' approach [1] rests on the intended mental set of the learner - in one case it involves requiring learners to demonstrate their ability to understand or produce specific linguistic features and in the other to engage in natural language use. Brumfit saw these two approaches as distinct but argued that both are needed in a language programme. He proposed an integrated curriculum with a variable emphasis on accuracy and fluency according to the learners' developmental stages. I will return to his arguments for an integrated syllabus later.

\section{Task-supported and task-based language teaching}

Task-supported language teaching (TSLT) and task-based language teaching (TBLT) both make use of 'tasks' (i.e. workplans designed to provide opportunities for using language 
under real-operating conditions). However, tasks have very different functions in TSLT and TBLT. TSLT draws on a Type A syllabus, it is product-oriented, and it involves an accuracyoriented approach. In contrast, TBLT draws on a Type B syllabus, is process-oriented, and constitutes a fluency-based approach although with attention to form built in through the design of tasks and through their implementation. In other words, tasks are simply methodological devices for practising specific structures in TSLT but serve as the means for defining the content of TBLT.

The intended mental set created by a task differs markedly in TSLT and TBLT. In the former, a task aims to provide opportunities for learners to display correct use of an explicitly taught target language feature while trying to achieve a communicative outcome. In the latter, a task aims to provide opportunities for using language naturally in order to achieve a communicative outcome. In both cases it is anticipated that learners will pay attention to form but in TSLT students are directed to attend to a pre-determined form whereas in TBLT attention to form arises incidentally while learners are performing the task.

For TSLT focused tasks are required - that is tasks that are designed in such a way as to create contexts for the use (receptively or productively) of pre-determined target features (i.e. those features that have been explicitly taught). Focused tasks can also figure in TBLT and indeed have been used in a large number of studies that have investigated tasks (e.g. Doughty and Varela, 1998; Lyster, 2004; Mackey, 1999). But when focused tasks are used in TBLT there is no attempt to make learners aware of the linguistic feature targeted by the task prior to the performance of the task. Focused tasks may or may not be successful in eliciting use of the target feature (Loschky and Bley-Vroman, 1993) [2]. An important issue, then, is whether such tasks are more effective in eliciting use of the target feature when learners' attention is explicitly directed to it as in TSLT than when it is not as in TBLT. Another key issue is whether the general quality of language produced (i.e. its complexity, global accuracy and fluency) differs when a focused task is performed in TSLT (with a priori explicit instruction) and TBLT (with no a priori explicit instruction) [3]. In short, we need to know whether explicit instruction affects how focused tasks are performed.

Some advocates of TBLT, however, (e.g. Long, 2015; Skehan, 1998), reject what they call 'structure tapping tasks' and argue for the use of only unfocused tasks (i.e. tasks designed to elicit only general samples of language) supported by a well-established set of methodological procedures for drawing learners' attention to form as they perform the tasks. These involve 'focus on form', defined by Long (2015) as the 'reactive use of a wide variety of pedagogic procedures to draw learners' attention to linguistic problems in context, as they 
arise during communication' (p. 317). Long sees such procedures as relating only to TBLT. However, the procedures that Long has in mind (e.g. corrective feedback strategies) are equally applicable to TSLT (Nassaji and Fotos, 2007). At the discourse level, strategies for focusing attention on form are applicable and relevant to both types of teaching (see Ellis, 2016) although it is an open question whether the learners' response to these procedures is the same in TSLT and TBLT.

TSLT and TBLT draw on very different theories of language learning. TSLT is based on skill-learning theory as this has been applied to language learning (DeKeyser, 1998). This theory claims that learning commences with a declarative representation of a linguistic feature, which is first proceduralized and then automatized through practice. DeKeyser (1998) distinguished two types of practice needed to effect the change from declarative to automatized procedural knowledge. In communicative drills learners can draw on 'declarative crutches' to assist proceduralization. More open-ended activities - i.e. tasks facilitate automatization. The theory then lends support to presentation-practice-production (PPP), the main way in which TSLT has been realized and arguably the mainstream methodology in structural language teaching today. DeKeyser was careful to recognize the limitations of PPP. First, he acknowledged that the L2 knowledge that results may not be true implicit knowledge (i.e. the kind of knowledge that arises during first language acquisition) but rather automatized explicit knowledge. However, he also argued that such knowledge is 'functionally equivalent' to implicit knowledge and so is sufficient for communicative purposes. More seriously he also suggested that skill-acquisition theory is "most easily applicable" to "the learning of simple structures" (DeKeyser, 2015; 101) and that only learners with a high aptitude for language learning are able to master complex structures (DeKeyser, 2000). Examples of simple structures are English plural $-\mathrm{s}$ and interrogative word order; examples of complex structures are English articles and subject-verb inversion after negative adverbials such as 'rarely'. The caveats that DeKeyser raises are important as they suggest that while TSLT may serve to develop a basic L2 competence for most learners it may not be effective for developing more advanced levels of competence [4].

In contrast, TBLT draws on research-driven theories of L2 acquisition that emphasize the importance of social interaction, usage-based learning, and implicit or incidental acquisition. Research demonstrating that there is a natural order and sequence of acquisition for grammatical features (Ellis, 2008; Chapter 3) constitutes evidence for a built-in learner syllabus that cannot be easily subverted through form-focused instruction. In TBLT, L2 learning is implicit - 'the default learning mechanism' (Long, 2015) - with learners following 
their own learning path to the target grammar. The aim is to provide contexts for this mechanism to operate. However, even though 'incidental and implicit learning remain options for adult learners' (p. 45) because there is a decrease in learners' ability to learn implicitly after the critical period, Long argued that instruction needs to make linguistic forms - especially those that learners fail to learn naturally - salient through the use of focus on form procedures. TBLT, then, aims to enhance natural learning processes through focus on form.

TSLT, as realized via PPP. and TBLT are not just seen as alternative approaches to teaching an L2 but as incompatible. This is apparent in the critiques that have been levelled at TBLT by advocates of TSLT (e.g. Sheen, 1994; Swan, 2005) and also by the position adopted by some advocates of TBLT (e.g. Long, 2015). Swan, for example, argued that those SLA researchers who promote TBLT "legislate by hypothesis" and disputed the validity of the hypotheses he saw as underpinning TBLT (i.e. the Online, Noticing and Teachability Hypotheses) on the grounds that there was insufficient evidence to support them. Sheen (2006) claimed that there is no evidence that TBLT is more effective than TSLT and reported his own study which he claimed showed the superiority of TSLT [5]. However, many of the points raised by Sheen and Swan are invalid, displaying a misunderstanding of what TBLT is and an ignorance of the relevant research - see Ellis (2009) and Long (2016) for refutations of their objections. Long (2015), on the other side of this debate, claimed that TSLT and TBLT are incompatible because they are based on different psycholinguistic theories (as outlined above). He emphasized the fundamental difference between TSLT as 'synthetic' and TBLT as 'analytic' and dismissed the focused tasks used in TSLT as 'counterfeit' tasks - 'little more than activities and exercises relabelled as tasks', (p. 6). Interestingly, however, he did acknowledge that TSLT has its champions and, citing Shehadeh (2005), suggested that it might serve "as a bridge between traditional synthetic syllabi and genuine task-based approaches" (p. 7). However, he did not elaborate on how this bridge might be constructed.

To sum up this section, TSLT and TBLT constitute different ways of using tasks in language teaching. The former is synthetic and product-oriented, drawing on a structural syllabus and an accuracy-oriented methodology. The latter is analytic and process-oriented, drawing on a task-based syllabus and a fluency-oriented methodology. TSLT and TBLT are based on different learning theories, skill-learning theory in the case of TSLT and usagebased theories of implicit/ incidental learning in the case of TBLT. In both TSLT and TBLT, however, the same set of focus-on-form procedures are needed. TSLT and TBLT are often 
presented in the literature as alternative ways of teaching and incompatible, each with its own advocates.

In the following section I want to challenge the view that because TSLT and TBLT are incompatible they cannot be combined in a curriculum. I will draw on both Brumfit's (1984) educational arguments for combining accuracy and fluency approaches and on my own theory of second language learning (Ellis, 1994) to argue the need for a curriculum that combines a product-based component realised through TSLT and a process-based component realised through TBLT. Later I will consider how these two components can be organized in a curriculum. In so doing I will try to flesh out Spada's (1997) proposal for a curriculum that combines communicative and form-focused components.

\section{The compatibility of task-supported and task-based language teaching}

The educational case for adopting a curriculum that integrates task-supported and task-based language teaching was convincingly made by Brumfit (1984) some time ago. His starting point was:

We seem to have two different types of information available to us for incorporation in a syllabus: that which is capable of systematization, and that which is not. (p. 101) Brumfit argued that a syllabus cannot be just "a random joining together of elements with no particular cohesion or system" (p. 98. He argued that even if a structural syllabus does not accord with the learners' internal syllabus, this does not warrant discarding it and noted that "insofar as we wish to make our language teaching coherent to either learners or teachers, we have little choice but to turn to the systems of linguists" (p. 94).

Brumfit's case for a product syllabus, however, goes beyond the need for systematicity. He recognized that "the key issue will be the expectations about the nature of learning ... which students bring to the school" (p. 100) and argued that "a syllabus will also have to operate in the real educational world" (p. 117). This is a position more recently taken up by Littlewood (2014), who challenged the feasibility of task-based teaching in the Chinese context on the grounds that it is ill-suited to the traditional Chinese culture of learning, where 'education is conceived more as a process of knowledge accumulation than as a process of using knowledge for immediate purposes' (p. 653). Littlewood listed a whole range of problems that he argued make the successful implementation of TBLT difficult and perhaps 
impossible in such a context - the problem of using TBLT in large classes, the excessive demands that TBLT makes on the language skills of teachers with limited communicative ability, the need for new organizational skills required for group work, the tendency of students to talk in the mother tongue when performing tasks, students' beliefs that language learning involves the item-by-item progression through a syllabus, and teachers' commitment to the traditional view of teaching as the transmission of knowledge [6]. While Littlewood overstates the difficulties involved in introducing TBLT, many of the problems he mentions warrant serious attention. It was Littlewood's conviction that TBLT is impractical in contexts such as China that led him to argue in favour of TSLT.

Brumfit, however, did not reach the same conclusion as Littlewood:

We have, then, a product-based syllabus in order to ensure that there are some controls on the activity that takes place in the classroom. But it is clear that the syllabus must also contain a process element (p. 117).

He saw the need for a "delicate balance between a specification which is so unrealistic as to prevent change, and one which is so conventional as to reinforce the past and equally prevent change" (p. 117). He acknowledged that "language is best memorised when the learner is exposed to suggestion rather than to overt and self-conscious presentation of the system" (p. 100) and considered the Bangalore Project (subsequently called the Communicational Teaching Project - Prabhu, (1987)) at length as an example of a process-syllabus and a fluency-based approach [7].

The key question, then, becomes how to combine product- and process-based approaches. Brumfit saw a linguistic syllabus as serving two purposes. It provides a structure for the initial teaching of linguistic tokens and it can be used as a checklist to enable teachers to check coverage and appropriacy of material. He was less clear, however, about the process element of the curriculum and did not take on board Prabhu's task-based syllabus. Instead, he emphasized the role of projects to provide opportunities for fluency work. Project work was to be supported through the presentation of relevant linguistic tokens of the target language (but avoiding over-exact analyses of the language to be so taught), input material that is comprehensible, interesting and relevant, and corrective feedback. Brumfit also made the important point that a syllabus does not dictate the methodology to be employed, thus allowing for the possibility that lessons motivated by a linguistic syllabus could incorporate fluency work - which is, in fact, exactly what TSLT seeks to achieve in the free-production stage of a lesson. The integrated model that Brumfit proposed is shown schematically in 
Figure 1 below. Accuracy and fluency work occur from the start (Year 1) but the balance changes over time, with accuracy work based on a linguistic syllabus dominating initially before giving way increasingly to fluency work involving projects as proficiency increases [8].

Figure 1: Brumfit's integrated curriculum model (p. 119)

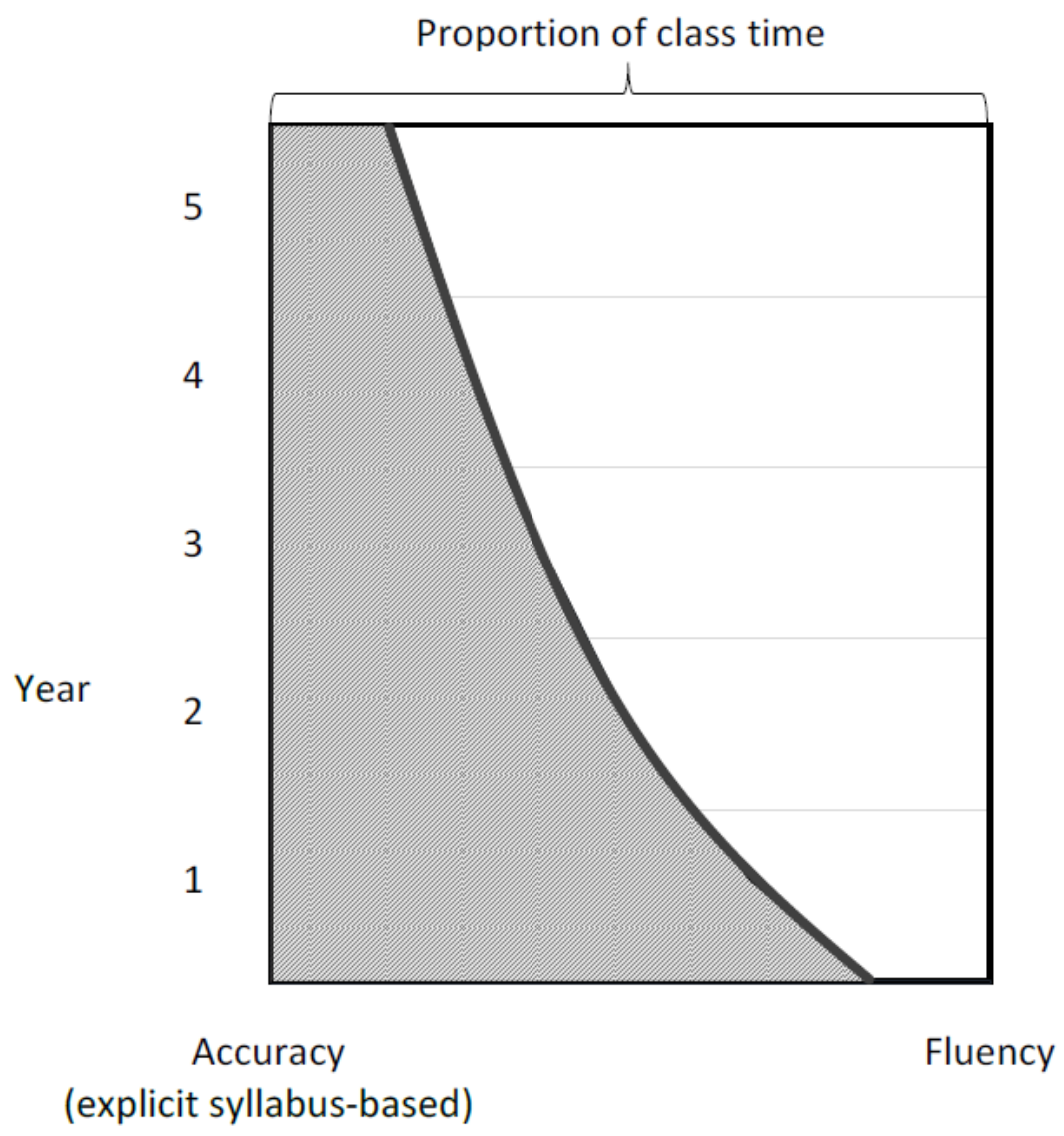

Where Brumfit drew mainly on educational arguments in support of an integrated curriculum, R. Ellis $(1993 ; 1994)$ drew on research in SLA to propose a theory of instructed language learning that lends support to both a task-based and a structural syllabus. Ellis' theory is founded on the distinction between implicit and explicit knowledge and, in particular, on the role that explicit knowledge plays in the development of implicit knowledge.

Ellis saw implicit knowledge as primary in the sense that without it communication is very difficult. The acquisition of grammatical features is a slow and gradual process, reflecting the psycholinguistic constraints that govern integration of new features into a learner's interlanguage system. In line with Schmidt's Noticing Hypothesis (Schmidt, 1990), he suggested that implicit learning is in part a conscious process as learners must notice new 
features in the input and also notice the gap between what they attend to in the input and their current interlanguage systems in order to learn. Implicit learning results in implicit knowledge, which is accessible via automatic processing and thus available for spontaneous, communicative language use. Explicit knowledge is secondary importance but still an important part of language proficiency as it is needed in some kinds of formal language work (e.g. academic writing). Ellis suggested that it is accessible mainly through controlled processing but can also be automated to some extent. It is typically learned through studying descriptions of grammatical rules or as a result of explicit instruction.

Ellis argued that the development of L2 proficiency proceeds largely through the processes responsible for acquiring implicit knowledge (e.g. noticing, noticing-the-gap, and chunking) - a view also promulgated by N. Ellis (1996). However, in Ellis' theory, explicit knowledge can contribute to this in a number of ways. In accordance with the weak-interface hypothesis Ellis argued:

(1) Explicit knowledge can be converted into implicit knowledge through practice in the case of those linguistic features that are not subject to developmental constraints (for example, copula 'be' in English). However, this is only possible if the learner is at a stage of developmental readiness to acquire a specific feature. See Pienemann's (1985) Teachability Hypothesis.

(2) Explicit knowledge can facilitate the processes of noticing and noticing-the-gap that lead to implicit knowledge. That is, learners are more likely to attend to features in the input and to the difference between the input and their current interlanguage if they have prior explicit knowledge of them.

(3) Explicit knowledge can be used to edit utterances constructed from implicit knowledge, which helps accuracy in language use and the automatization of explicit knowledge. In addition monitored output serves as a source of auto-input for implicit learning.

In the case of (1) there is a direct relationship between explicit and implicit knowledge as claimed by skill-learning theory although this is constrained by developmental readiness. In the case of (2) and (3) explicit knowledge contributes indirectly to the acquisition of implicit knowledge by facilitating the processes involved in implicit learning. Subsequently, Ellis (2006) emphasized these indirect roles and downplayed (1), which he saw having little relevance to language teaching because there is insufficient information about which features are developmental and non-developmental and because of the impracticality of establishing whether individual learners are developmentally ready to benefit from explicit instruction. In 
contrast the, the use of explicit knowledge for roles (2) and (3) are less dependent on learner readiness. The application of his theory that I discus below is therefore based on these indirect roles.

In Ellis (1993), the theory is applied to language pedagogy. He proposed a different role for the structural syllabus from its traditional role. Traditionally, a structural syllabus serves as a basis for developing implicit knowledge by means of TSLT. Ellis argued that this is problematic for the reasons that Long (1988) articulated so well - namely, the incompatibility of the external syllabus with the learner's built-in syllabus. Therefore, Ellis suggested that the function of a structural syllabus should be limited to developing learners' explicit knowledge, which is not subject to a built-in syllabus. He proposed this could be achieved through inductive consciousness-raising tasks aimed at helping learners to learn about specific linguistic features (i.e. develop explicit representations of how they function in the linguistic system). This more limited goal for a structural syllabus was justified on the grounds that explicit knowledge can subsequently facilitate the acquisition of implicit knowledge providing learners have on-going opportunities for incidental/ implicit learning.

Ellis' proposal - as Long (2015) has pointed out - provides support for TSLT. Long rejected it precisely because of this, claiming that it represented a return to traditional language teaching. However, in so doing he ignored the details of Ellis' proposal. Ellis was not arguing in support of TSLT but for an approach aimed solely at developing learners' explicit representations of linguistic features, which he suggested can best be achieved by means of consciousness-raising tasks . In other words, in Ellis' proposal there is no need for practice activities. The focus is on helping learners to discover how linguistic features work for themselves and then allowing them to make use of the explicit knowledge they gain in this way in their own time rather than trying to transform it into implicit knowledge through practice. Thus, in Ellis' theory a structural syllabus has a reduced purpose. It cannot serve as the basis for a complete language programme as it needs to be complemented by "other kinds of syllabuses that are based on the provision of input hypothesized to promote implicit knowledge - a functional or task-based syllabus" (p. 110).

Ellis (1993) acknowledged that the precise relationship between the structural component and the other component of the curriculum remained unspecified. The key issue here is the timing of the structural component. A number of options are possible:

1. The structural and task-based components of the syllabus operate in parallel from the start to the end of the curriculum. In other words, work on developing learners' explicit and implicit knowledge takes place throughout the curriculum. 
2. The structural component precedes the task-based or project-based component. In other words, the aim is to develop the learners' explicit knowledge before the introduction of the fluency-oriented component.

3. The task-based component precedes the accuracy-based structural component. In other words, the initial focus should be on fluency and the development of implicit knowledge with attention to target-language norms introduced later.

In the next section I will examine the arguments for these different options. However, it will first be necessary to consider whether the curriculum I have in mind should be an integrated or modular one.

\section{Designing a language curriculum}

None of the three options listed above correspond to TSLT although TSLT has a role in all of them. TSLT draws on a structural syllabus, with tasks providing the real operating conditions for proceduralizing declarative (explicit) knowledge. The problem with such an approach is that it prioritizes accuracy over fluency and assumes that implicit knowledge is mastered item by item, which as Long (2015) pointed out is not how an L2 is acquired. However, as I noted earlier, it is supported by skill-learning theory and there is certainly evidence to show that it can result in automatized knowledge that is at least functionally equivalent to implicit knowledge. See Norris and Ortega's (2000) meta-analysis of form-focused instruction studies. Nevertheless, it is still difficult to see how a structural syllabus and TSLT can serve as the basis for a complete language programme as (1) grammar is complex and there will not be enough time to provide the in depth practice needed for mastery of the full system (Krashen, 1982) and, in any case, (2) as I have already noted, TSLT may not be appropriate for complex grammatical features except perhaps for learners with a strong aptitude for language learning. Yalçin and Spada (2016), for example, reported a study that showed that instruction was only effective in helping those learners with high grammatical inferencing ability to acquire a complex grammatical structure (English passives). Another reason is that explicit instruction may in fact distort how tasks are performed, reducing their effectiveness as tools for developing L2 proficiency in general (see Note 3). The curriculum that I wish to argue for, therefore, is not a structural one although, as will become clear, such a syllabus along with explicit language teaching can find a place in a modular curriculum.

The three options referred to above assume a modular syllabus rather than a syllabus where the structure-based accuracy component and the task-based fluency component are fully 
integrated. In this respect, the proposal I want to advance differs from Brumfit's proposal. Brumfit quite clearly favours integration at the level of the syllabus. This lies at the centre of his accuracy/ fluency distinction. Irrespective of whether the learning activities are based on the structural component or on the project component of the syllabus, he argued that attention to both accuracy and fluency can and should be integrated throughout. In contrast, in the modular curriculum I am proposing, the structural and task-based components of the syllabus are kept separate. However, as I will shortly argue, this does not preclude the possibility of finding ways of integrating accuracy and fluency methodologically in the performance of specific activities. Before I consider how this can be achieved, however, I will discuss the four options for a modular syllabus.

In option 1, work on developing learners' explicit and implicit knowledge takes place contiguously and in parallel. As in Brumfit's model (see Figure 1), the proportion of class time allocated to the different components varies over the course of a language programme. However, this option differs from Brumfit's as at any stage there will be separate lessons directed at developing explicit and implicit knowledge. In the case of the task-based component learners will perform unfocused tasks supported by focus on form. In the case of the structural component, they will experience TSLT directed at developing explicit knowledge of target features. The model does not presuppose integration of the two components. The rationale for separation is that the integration of explicit and implicit knowledge must necessarily be learnerdriven and cannot be directed externally through instruction. Learners need to be left alone to make use of the knowledge they gain from the structural component of the curriculum in their own way and in their own time when they engage in activities derived from the task-based component. The advantage of this option is that it may help to prevent pidginization, which some commentators such as Seedhouse (1997) suggest occurs in a pure task-based approach, by encouraging learners to focus on accuracy from the start. The problem with this model, however, is that learners may not be able to make effective use of the knowledge they gain from the structural component in the early stages of L2 acquisition because they are not developmentally ready to do so. As SLA research has shown, implicit learning is usage-based, involving chunks that are only slowly decomposed into rule-like constructions (R. Ellis, 1984; N. Ellis, 1996). Thus some development - in particular lexical - needs to have occurred before learners are ready and able to make use of their explicit knowledge.

The second option (shown schematically in Figure 2) runs up against the same objection but even more so. It is nevertheless the model that is favoured by advocates of an accuracy-first approach - see, for example, Yalden, (1986 - and by teachers who believe that 
learners cannot be expected to perform tasks until they have acquired some grammatical knowledge of the target language. However, as R. Ellis (2002) pointed out, such a view does not accord with what is known about L2 acquisition. Immersion studies (e.g. Johnson and Swain, 1997) have shown that learners do not need grammatical instruction to acquire considerable grammatical competence. Basic word order and salient morphological features can be acquired incidentally without any formal instruction. If the early stages of L2 acquisition are lexical rather than grammatical (Lewis, 1993), there might be a case for an initial explicit component for teaching vocabulary but arguably, what is needed in the early stages is an approach that prioritizes incidental acquisition through the performance of tasks from the start. This would seem most obviously true for young language learners but is also preferable for older learners.

Figure 2: A modular curriculum (option 2).

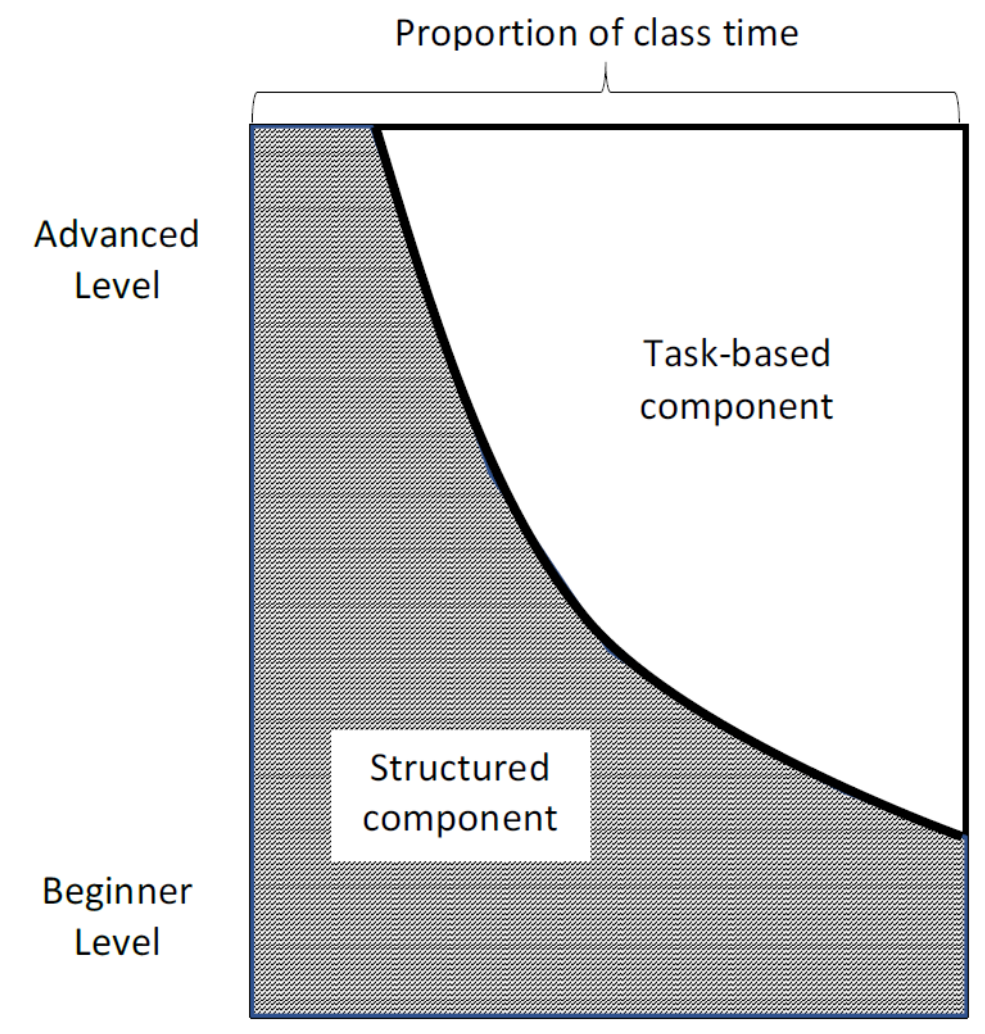

Option 3 (shown schematically in Figure 3) is more clearly compatible with how L2 proficiency develops naturally. As R. Ellis (2002) argued:

If grammar teaching is to accord with how learners learn, then, it should not be directed at beginners. Rather, it should await the time when learners have developed a sufficiently varied lexis to provide a basis for the process of rule-extraction. In crude terms, this is likely to be at the intermediate stages of development. (p. 23). 
This option then reverses the traditional sequence of instruction. It calls for a taskbased approach initially with the structural component kicking in at a later stage and continuing as long as learners provide evidence of the need for it. The task-based component, however, occupies the greater space in the model throughout. In other words, in this model priority is given to the incidental acquisition of implicit knowledge at all times in a language programme.

Although the curriculum framework I am proposing consists of separate components for task-based and structural work, as I noted above, there are opportunities for integrating a focus on form and on meaning-making methodologically. Brumfit proposed the explicit teaching of linguistic forms to assist the performance of project-based activities- as in TSLT in fact. Long's advocacy of a task-based syllabus is premised on unfocused tasks derived from a needs analysis of the target tasks relevant to specific groups of learners. It also depends crucially on the use of focus-on-form strategies that attract attention to those linguistic forms required to achieve the communicative outcome of a task and, thereby, help learners to approximate more closely to target language norms. Long's approach involves enhancing natural language learning by facilitating attention to form and so avoiding the danger of pidginization that can occur when there is nothing to push learners towards greater accuracy [9]. The problem with Brumfit's proposal is that learners may not be developmentally ready to benefit from explicit instruction in fluency-oriented work. The problem with Long's proposal, as Pica (1996) pointed out, is that focus-on-form (especially when it only consists of the negotiation of meaning) typically does not address some grammatical features such as morphological inflections and thus cannot guarantee their acquisition [10]. In other words, TBLT even with focus on form is unlikely to ensure that learners acquire high levels of grammatical accuracy. This is why an explicit structural component is needed to complement the task-based component. 
Figure 3: A modular curriculum (option 3)

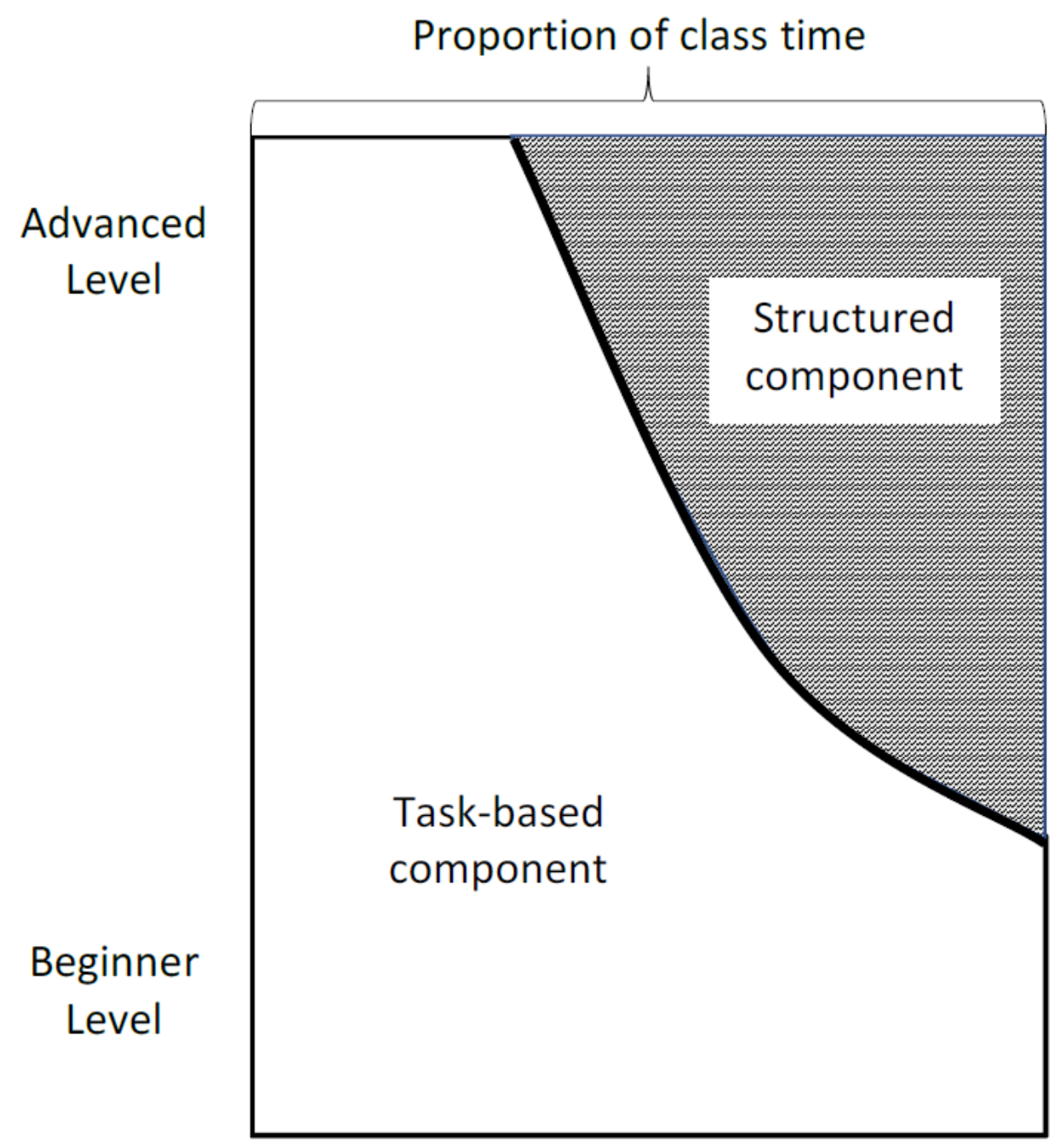

Earlier I suggested that one way of implementing a structural syllabus is by using consciousness-raising tasks to help learners construct explicit mental representations of linguistic rules and regularities. Such tasks, however, have a double purpose and thus potentially integrate a focus on form and a focus on communication within the same activity. In addition to developing awareness of linguistic forms, they function as problem-solving tasks where 'language' becomes the topic to be talked about. They conform to the definition of a task; that is, they are meaning centred in the sense that the talk they elicit is directed at solving a linguistic problem, there is a gap (it can be an information or opinion gap depending on the design of the task), they elicit the use of learners' own linguistic resources as the task is performed, and there is a communicative outcome (a statement of the rule or regularity the task focuses on). It is important to understand that consciousness-raising tasks do not aim at production of the target 
feature and do not require it. They elicit general talk in the L2. For evidence of these claims see studies by Fotos and Ellis (1991) and Eckerth (2008) [11].

To sum up, I have argued for a modular curriculum framework consisting of two separate components - a structural component and a task-based component - but with no attempt to integrate them at the level of syllabus. Of the three options for this framework, I have suggested that the one most compatible with what we know about L2 acquisition is option (3) where the task-based component is primary but - and it is this respect the model I am proposing differs most clearly from Long (2015) - there is a structural component to address residual problems with specific grammatical features once basic L2 proficiency has been developed. Some integration of structural and task-based work can take place at the level of methodology either by means of TSLT or through performing consciousness-raising tasks but the overall curriculum is modular with the emphasis on each component changing as a programme develops. Having presented the case for a modular curriculum, I will now turn to consider the content of the two components of the syllabus.

\section{Determining the content of the task-based and structural modules of the curriculum}

The design of a syllabus requires two kinds of decisions to be made: (1) which content to include and (2) how to sequence of the content so that there is progression from simple to complex. In a modular syllabus, the content of the task-based component will consist of the tasks to be performed while in the structural component it will consist of a list of grammatical structures. The principles and procedures for sequencing the content of the two components are necessarily different.

\section{Content in the task-based syllabus}

In the case of specific purpose courses, the obvious way to ensure the relevancy of a task-based syllabus is to conduct a needs analysis to identify the target tasks that the learners need to be able to perform. Long $(1985 ; 2015)$ suggested that specific target tasks can be grouped together into task types (for example, 'buying a railway ticket' and 'buying an airline ticket' could be grouped as 'buying a ticket') and then pedagogic tasks developed to ensure that the activities meet the requirements of a 'task'. However, other commentators have pointed out that it is not always possible or sensible to try to identify target-tasks. Cameron (2001), for example, maintained that a needs-based syllabus is not feasible for young foreign language learners. Also, there is the problem of determining just how 'general' the task-types have to be. Van Avermaet 
and Gysen (2006) questioned whether any transfer of learning from the performance of one task to another task of the same type can be expected. It does not follow, for example, that because learners can 'buy a railway ticket', they can also 'buy an airline ticket' even though both belong to the same task type. The central problem of Long's $(1985 ; 2015)$ proposal, however, lies in whether language proficiency is best conceptualized as domain and task-specific or as a set of general abilities applicable across task types and situations. If the latter, then, arguably there is no reason for the content of the task-based component to be derived from a needs analysis of target tasks.

The alternative is to select tasks that have interactional authenticity without undue concern for their situational authenticity (see Bachman and Palmer, 1996). Interactional authenticity can be achieved by ensuring that the tasks meet the requirements for a task mentioned earlier. There is, however, still the important question of what topics the tasks should address. Ideally these should motivate learners' engagement with the tasks (Philp and Duchesne, 2016). However, there are dangers in syllabus designers basing the choice of topics on their own judgment; ideally students should be consulted about what topics interest them. In the case of task-based courses based on academic subject content as in immersion programs, the choice of topics will be derived from the relevant subject syllabi.

The syllabus designer needs to decide whether the syllabus should specify the specific pedagogic tasks to be performed or just general types of tasks. Prabhu (1987) argued that if the syllabus is intended as a basis for teaching on a large scale (for example, in state school systems), the tasks are best specified in general terms. The examples he provided are task types specified in terms of (1) their topics (e.g. maps; school timetables) and (2) the particular operations a task stipulates (e.g. 'Finding, naming or describing specific locations on a given map'; 'Constructing class timetables from instructions/ descriptions'). For each task type Prabhu proposed a number of different tasks that differed in the kinds of operations they involved.

Prabhu's proposal for designing a general task-based syllabus remains one of the most practical to date. It provides a basis for both the vertical and horizontal grading of tasks in the syllabus. Vertical grading in Prabhu's syllabus is achieved by sequencing the different task types; horizontal grading is achieved by considering the difficulty of the operations involved in the particular tasks belonging to each task type. In Table 1 I have illustrated vertical and horizontal grading using examples take from Prabhu's syllabus.

Table 1: Horizontal and vertical dimensions of a task-based syllabus (based on Prabhu, 1987; $138-9)$ 
$\begin{array}{ll}\text { Task Types } & \text { Task } \\ \text { operations }\end{array}$

\begin{tabular}{|c|c|c|c|}
\hline $\begin{array}{l}\text { Clock } \\
\text { faces }\end{array}$ & $\begin{array}{l}\text { Relating } \\
\text { days to days } \\
\text { of the week }\end{array}$ & $\begin{array}{l}\text { Calculating } \\
\text { durations } \\
\text { from } \\
\text { movement of } \\
\text { a clock's } \\
\text { hands }\end{array}$ & $\begin{array}{l}\text { Stating the } \\
\text { time on a } \\
\text { twelve and a } \\
\text { twenty-four } \\
\text { hour clock }\end{array}$ \\
\hline $\begin{array}{l}\text { Monthly } \\
\text { calendars }\end{array}$ & $\begin{array}{l}\text { Relating } \\
\text { dates to days } \\
\text { of the week }\end{array}$ & $\begin{array}{l}\text { Calculating } \\
\text { durations in } \\
\text { days and } \\
\text { week in the } \\
\text { context of } \\
\text { travel }\end{array}$ & $\begin{array}{l}\text { Identifying } \\
\text { relevant dates } \\
\text { or days of the } \\
\text { week in } \\
\text { relation to } \\
\text { cyclic activity }\end{array}$ \\
\hline $\begin{array}{l}\text { School } \\
\text { timetables }\end{array}$ & $\begin{array}{l}\text { Constructing } \\
\text { class } \\
\text { timetable } \\
\text { from } \\
\text { instructions/ } \\
\text { descriptions }\end{array}$ & $\begin{array}{l}\text { Comparing } \\
\text { such } \\
\text { timetables to } \\
\text { identify } \\
\text { frequencies } \\
\text { of lessons in } \\
\text { different } \\
\text { subjects }\end{array}$ & $\begin{array}{l}\text { Constructing } \\
\text { timetables for } \\
\text { teachers of } \\
\text { particular } \\
\text { subjects from } \\
\text { class } \\
\text { timetables }\end{array}$ \\
\hline
\end{tabular}

The construction of a general task syllabus should be informed by principles for determining both the vertical sequence of task types and the horizontal sequencing of task operations. Prabhu did not make explicit what principles should inform the sequencing of task types. An inspection of his syllabus, however, suggests that one general factor he considered was the potential familiarity of the topics of the tasks. Thus, for example, his early task types all involve topics that eleven-year-old secondary students could be expected to be familiar with. Later task types (e.g. 'the postal system" and 'stories and dialogues') involve less familiar topics and imagination. Estaire and Zanon (1994) also proposed sequencing task types in terms of how close or remote to the lives of the students the topics are and suggested this sequence: 
- the students themselves,

- their homes,

- their school,

- the world around them and

- fantasy/ imagination.

There are also other factors that need to be considered in vertical sequencing. Prabhu advocated a general progression:

information gap $\rightarrow$ reasoning gap $\rightarrow$ opinion gap tasks.

Ellis (2015) proposed that the first task types should be input-based with closed outcomes with output-based tasks involving open outcomes introduced progressively at later stages.

Grading and sequencing for the horizontal dimension requires identifying the specific task characteristics that determine task complexity. Prabhu suggested a number of factors that need to be considered - the amount of information to be handled, the nature of the reasoning needed, the precision needed in interpreting information and reaching outcomes, and the degree of abstractness. These are very general characteristics, however. Subsequently, attempts have been made to identify more specific design features that determine complexity and then to investigate these empirically. Robinson (2011) argued that a taxonomy of task characteristics is needed which can serve as "a focus for concerted research into the effects of those characteristics on learning" (p. 17) and also as a basis for classifying and sequencing tasks. According to Robinson's Triadic Componential Framework (Robinson, 2010), the resource-directing characteristics of tasks (e.g. +/- few elements; +/- here-and-now; +/- no reasoning demands) determine task complexity and provide "a parsimonious way to sequence L2 tasks in a program of instruction" p. 10). [12]. Tasks with the + features are presumed to be less complex than tasks with the - features. Resource-dispersing factors such as pre-task planning can be combined with resourcedirecting variables to reduce the processing load and thus assist automaticity, as in this example:

Pedagogic task 1: - reasoning/ + planning time.

Pedagogic task 2: - reasoning/ - planning time

Pedagogic task 3: + reasoning/ + planning time. 
Pedagogic task 4: + reasoning/ - planning time

Robinson's framework provides a useful way of sequencing tasks horizontally [13] but it is not without problems.

The strength of his approach is that it aims to provide an empirically-supported basis for sequencing tasks according to their complexity. However, to date research based on his taxonomy has failed to support Robinson's central claim convincingly, namely that more complex tasks result in L2 production that is both more complex and more accurate. Jackson and Suethanapornkul's (2012) meta-analysis of studies based on Robinson's taxonomy did not support this claim. The obvious problem with a taxonomic approach to determining task complexity is that tasks are holistic in nature and thus comprise clusters of features. Thus, there needs to be some metric for determining how combinations of different resourcedirecting and resource-dispersing features affect task complexity and L2 output but no such metric is currently available. The example above manipulates just two features but there are many more features that figure in Robinson's taxonomy. Perhaps in the long term, research will be able to show which combinations of features are optimal for determining horizontal sequencing. Some progress in this direction has been made (see, for example, Sasayama, 2016) but there is still no agreement about specific features that need to be investigated, and individual researchers do not operationalize those features that figure in Robinson's theory in a consistent manner so that results cannot easily be compared across studies. We are a long way from a convincing theory of task complexity and perhaps such a theory is not achievable, given the nature of tasks.

It should be clear from the preceding comments that there is no algorithm for selecting tasks and grading them in order to sequence them vertically and horizontally. All that is available are some common-sense notions (such as topic familiarity and learners' interests) supported by research that has identified specific design variables that affect task complexity. So for the time being and probably for a long time syllabus designers will have to draw on their experience and intuition, informed by taxonomies such as Robinson's, to decide how to sequence tasks. Designing a task syllabus must, for the time being at least, be as much an art as a science.

\section{Structural content}

The principles for selecting and grading the content of the grammatical content of a syllabus are well-established although not perhaps empirically motivated. They are reflected in the 
very considerable uniformity in the ordering of grammatical structures in a structural syllabus. Yalden (1983) found a remarkably similar order in four audiolingual textbooks. No substantial changes have taken place since except to try to link the teaching of grammatical forms to particular situations, topics or themes as in Swan and Walter (1984) or Soars and Soars (2013). The limitations of the structural syllabus are well-established and have already been considered, but note should be taken that a structural syllabus does at least provide a systematic basis for a language programme, as Brumfit (1984) pointed out. In the modular curriculum I am proposing, however, the structural component takes the form of a checklist rather than a syllabus.

The essential difference between a syllabus and a checklist is that the former specifies both what is to be taught and the order in which is taught whereas the latter consists only of a list of items with no expectation that teachers will follow the order in which the items are listed or, indeed, teach all of the items. In other words, if the structural content is presented as a checklist there is no need to address the thorny problem of how to grade and sequence structural items. There is, however, still the question of which items to include in the checklist. And some guidance will be needed about when specific items should be addressed - an issue I address below.

A checklist serves as a reference for observing whether learners are able to use specific linguistic features accurately when communicating. That is, as previously noted, in the modular curriculum shown in Figure 3 learning progresses primarily incidentally/ implicitly through performing tasks but a check is needed to see if learners have mastered specific grammatical features. Ideally, then the content of the checklist should reflect those grammatical structures that are known to be difficult for learners to acquire incidentally. We now have a fairly good idea of what these problem structures are - see, for example, Han's (2014) research on fossilized L2 forms. They include structures where entrenchment of nontarget forms occurs due, in particular, to learned selective attention (N. Ellis, 2006). Two processes interfere with the learners' ability to attend to new information in the input. Overshadowing occurs when two cues are associated with an outcome and the more subjectively salient of the two cues overshadows the weaker. This results in blocking where the learner only attends to the more salient of the two cues. Causes of learned selective inattention are the learner's L1, the inherent saliency of one cue over another, and the overgeneralization of an unmarked linguistic form. Examples of English structures that are subject to overshadowing and blocking are morphological features such as past tense, third person-s, epistemic modal verbs, the definite and indefinite articles, passive constructions, 
hypothetical conditionals, and unusual or exceptional word orders (e.g. subject-verb inversion after a negative-meaning adverbial such as 'scarcely' or in embedded questions). To a large extent, these errors are universal. The extensive work in error analysis on lateacquired linguistic features that has taken place over the years together with consultations with experienced teachers about the persistent errors that they have observed in their learners provide a basis for selecting which grammatical forms to include in the structural checklist.

The purpose of the structural component of a modular curriculum is to overcome the adverse effects of learned selective attention through explicit instruction - either through TSLT or consciousness-raising tasks.

However, the structural checklist is only suggestive of the problems that particular groups of learners are likely to experience. It will be necessary for teachers to obtain evidence whether their learners are actually experiencing difficulties with specific structures in the list. This can only be obtained by inspecting how they perform the tasks in the taskbased component of the syllabus. If, for example, it becomes clear that learners are persistently failing to use past tense in narrative tasks, it would justify the direct teaching of past tense, not necessarily with the aim of eradicating such errors immediately but rather of developing explicit knowledge to facilitate the processes involved in mastering past tense over time. The decision to intervene in this way calls for considerable skill on the part of the teacher. For example, a close inspection of learners' use of the past tense might reveal that the verb is not marked in contexts when there is an accompanying adverb but is marked when there is no adverbial expression. A well-designed checklist would provide guidance as to how linguistic context influences the likelihood of errors occurring.

\section{Conclusion}

Any curriculum must take account of how languages are learned. The primary rationale for a task-based curriculum is that it is learning-centred. It seeks to create communicative contexts that will allow learners' to grow their interlanguages in their own way while helping them to do so through focus-on-form. There is now clear evidence that a task-based curriculum is effective in enabling learners to develop both the linguistic and interactional competence needed to communicate in an L2 (De Ridder et al, 2007; González-Lloret and Nielson, 2015; Shintani, 2016; Van den Branden, 2006). However, a task-based curriculum may not succeed in enabling learners to achieve high levels of linguistic accuracy. Long (2015) acknowledged that some L2 forms are 'tricky, perhaps because of L1 influence' (p. 28) and also that 
explicit attention to such form might be needed. He argued, however, that this should be reactive and occur only within the context of the task-based lesson - "sometimes just for a matter of seconds" - as focus-on-form. This should clearly be the first line of attack. However, experience suggests that it may not succeed in overcoming learned selective attention. It is for this reason that I have argued there is a need for a complementary strand to the curriculum where residual linguistic problems are addressed more intensively through TSLT or consciousness-raising tasks.

It could be argued, however, that these residual problems are not addressable - that once past the critical period L2 learners will be unable to master the full target language. This would be an argument for a pure task-based curriculum on the grounds that it is the best that can be achieved. However, there is plenty of evidence (e.g. Harley, 1989; Day and Shapson, 1991) that functional grammar teaching of the TSLT kind is effective in helping learners achieve higher levels of accuracy for problematic grammatical structures. Thus I have argued for a modular curriculum where the task-based component is primary, but supported by a language-related component consisting of a checklist of problematic linguistic features that can guide explicit language teaching in a way that is complementary to the task-based work. I have also argued that- contrary to Long's (2015) claim - the two approaches are not incompatible. TSLT may not result in implicit knowledge but it may lead to automatized explicit knowledge that is functionally equivalent to implicit knowledge - a useful substitute. Consciousness-raising tasks can help develop the explicit knowledge of grammatical structures that will facilitate the processes involved in incidental/ implicit learning. I have acknowledged the difficulty of integrating explicit language instruction into a task-based curriculum and for this reason I have argued for separate modules. Finally I reiterate the arguments advanced by Brumfit (1984) and Littlewood (2014) that cognizance must be taken of the constraints imposed by the educational context and that in some contexts it may be easier to implement a task-based if it is supported by a structural component.

\section{Notes}

1. Brumfit's use of the terms 'accuracy' and 'fluency' differ from how these terms are used in task-based research. For Brumfit, they were not aspects of language use but methodological approaches to teaching language. For researchers such as Skehan (1998) they were aspects of language production. 
2. Focused tasks are sometimes successful in eliciting productive use of the target structure (e.g. in Mackey, 1999). Dictogloss tasks have proven effective in this respect.

3. There is in fact very little research that has investigated what effect a priori explicit instruction has on the performance of a task. Mochizuki, N. and Ortega, L. (2008) reported a study that found explicit instruction resulted in greater accuracy in the use of the target structure with no negative effects on fluency and complexity. In Li et al (forthcoming), however, the explicit instruction did not lead to greater accuracy and did have detrimental effect on fluency and complexity. Clearly, if TSLT has a deleterious general effect on fluency and complexity, it will not promote the kind of balanced development that researchers such as Skehan (1998) see as the goal of TBLT.

4. The fact that TSLT (PPP) might not be effective for teaching complex structures does not necessarily mean that it is any less successful in this respect than TBLT as, arguably, such structures are resistant to learning no matter what the approach.

5. Sheen's (2006) study is, however, methodologically flawed. A much better designed study - Shintani (2016) - reported that TBLT resulted in superior learning to TSLT for young beginner level learners.

6. Long (2016) also acknowledged that there may be problems in teachers' implementing TBLT but argued that this can be addressed through training programmes and cited the Belgian experience reported in Van den Branden (2006).

7. Long and Crookes (1992) viewed Prabhu's Communicational Language Teaching Project as based on what they called a 'procedural syllabus' which they distinguished from a 'task-based syllabus' on the grounds that only the latter incorporates a focuson-form.

8. Brumfit's curriculum model incorporates what Yalden (1986) called a 'proportional syllabus', where the proportions of different components change over time.

9. Long (2015) views focus-on-form as a purely reactive phenomenon - that is it should take place only in response to a linguistic of communicative problem. Ellis (2016), however, has argued that this is an over narrow view of focus-on-form and that learners can be induced to pay attention to form both proactively (as when they are given pre-task planning time) and pre-emptively (as when the teacher or a student attempts to prevent a problem arising). 
10. It might be argued that there is a better chance of guaranteeing a high level of grammatical competence through task-based language teaching if the focus-on-form is not restricted to the negotiation of meaning but also includes the negotiation of form - as, in fact, Long (2015) recognized. Even so, certain non-salient grammatical features are still unlikely to be acquired.

11. Long (2015) viewed consciousness-raising tasks as 'exercises'. This, however, is a misunderstanding. Long failed to recognize that when performed such tasks involve 'talk' (including the negotiation of meaning and form) in much the same way as other types of tasks.

12. Robinson did not explicitly limit his resource-directing characteristics to production tasks but it would seem that this is the case. The research based on his taxonomy has invariably concerned production tasks. Arguably a different set of criteria will be needed to grade input tasks. See Duran and Ramant (2006) for suggestions about this.

13. The sequencing shown in this example can work in two ways. One possibility is that the same task is repeated under the different conditions. Another possibility is that different but similar tasks are used in the sequence.

\section{References}

Bachman, L. \& Palmer, A. (1996). Language testing in practice. Oxford: Oxford University Press.

Brumfit, C. (1984). Communicative methodology in language teaching. Cambridge: Cambridge University Press.

Cameron, L. (2001). Teaching languages to young children. Cambridge: Cambridge University Press.

Day, E. \& Shapson, S. (1991). Integrating formal and functional approaches to language teaching in French immersion: an experimental study. Language Learning, 41, 25-58.

DeKeyser, R. (1998). Beyond focus on form: cognitive perspectives on learning and practicing second language grammar. In C. Doughty and J. Williams (eds.). Focus on form in classroom second language acquisition (pp. 42-63). Cambridge: Cambridge University Press.

DeKeyser, R. (2000). The robustness of critical period effects in second language acquisition. Studies in Second language Acquisition, 22, 499-533. 
DeKeyser, R. (2015). Skill acquisition theory. In B. VanPatten \& J. Williams (Eds.). Theories of second language acquisition ( $2^{\text {nd }}$ Ed. pp. 91-112). New York: Routledge.

De Ridder, I., Vangehuchten, L., \& Sesena Gomaz, M. (2007). Enhancing automaticity through task-based language learning. Applied Linguistics, 28, 309-315.

Doughty, C., \& Varela, E. (1998). Communicative focus on form. In C. Doughty \& J. Williams (Eds.), Focus on form in classroom second language acquisition (pp. 114138). Cambridge: Cambridge University Press.

Duran, G. and Ramaut, G. 2006. 'Tasks for absolute beginners and beyond: Developing and sequencing tasks at basic proficiency levels'. In Van den Branden (ed.) pp.47-75.

Eckerth, J. (2008). Task-Based Language Learning and Teaching - Old Wine in New bottles?” In J. Eckerth \& S. Sickmann (Eds.). Task-based language learning and teaching: Theoretical, methodological, and pedagogical erspectives (pp. 13-46). Frankfurt am Main: Peter Lang.

Ellis, N. (1996). Sequencing in SLA: phonological memory, chunking, and points of order. Studies in Second Language Acquisition, 18, 91-126.

Ellis, N. (2006). Selective attention and transfer phenomena in SLA: contingency, cue competition, salience, interference, overshadowing, blocking and perceptual learning. Applied Linguistics, 27, 164-194.

Ellis, R. (1984). Formulaic speech in early classroom second language development. In J.

Handscombe, R. Orem \& B. Taylor (Eds.). On TESOL'83: The question of context ( pp. 53-66). Washington D.C.: TESOL.

Ellis, R. (1993). Second language acquisition and the structural syllabus. TESOL Quarterly, 27, 91-113.

Ellis, R. (1994). A theory of instructed second language acquisition.” In N. Ellis (Ed). Implicit and explicit learning of languages (pp. 79-114). San Diego: Academic Press. Ellis, R. (2002). The place of grammar instruction in the second/foreign language curriculum. In E. Hinkel \& S.Fotos (Eds.) New perspectives on grammar teaching in second language classrooms (pp. 14-34). Routledge: London.

Ellis, R. (2006). Current issues in the teaching of grammar. TESOL Quarterly, 40, 83-107.

Ellis, R. (2008). The study of second language acquisition. $2^{\text {nd }}$ Edition. Oxford: Oxford University press.

Ellis, R. (2016). Focus on form: a critical review. Language Teaching Research, 20, 405428. 
Ellis, R. (2017). Moving task-based language teaching forward. Language Teaching, 50(4), 507-526.

Estaire, S. \& J. Zanon. (1994). Planning classwork: a task based approach. Oxford: Heinemann.

Fotos, S., \& R. Ellis. 1991. Communicating about grammar: a task-based approach.” TESOL Quarterly, 25, 605-28.

Halliday, M. (1973). Explorations in the functions of language. London: Edward Arnold.

González-Lloret, M. and Nielson, K. (2015). Evaluating TBLT: The case of a task-based Spanish program. Language Teaching Research,19, 525-549.

Han, Z.H. (2014). From Julie to Wes to Alberto: Rvisiting the construct of fossilization. In ZH. Han \& E. Tarone (Eds.). Interlanguage: Forty years later (pp. 347-74). Amsterdam: John Benjamins.

Harley, B. (1989). Functional grammar in French immersion: a classroom experiment. Applied Linguistics, 19, 331-59.

Hymes, D. (1970). On communicative competence. In J. J. Gumperz \& D. Hymes (Eds.). Directions in Sociolinuistics. New York: Holt, Rinchart and Winston.

Jackson, D.O., \& Suethanapornkul, S. (2012). The cognition hypothesis: a synthesis and meta-analysis of research on second language task complexity. Language Learning, 63, 330-367.

Johnson, R.K. \& M. Swain. (1997). Immersion education: international perspectives. Cambridge: Cambridge University Press.

Krashen, S. (1982). Principles and practice in second language acquisition. Oxford: Pergamon.

Lewis, Michael (1993), The lexical approach, Hove: Language Teaching Publications. Li, S. and Ellis, R (forthcoming). The influence of pre-task grammar instruction on task performance and L2 learning in task-supported language instruction: A processproduct study.

Littlewood, W. (2014). Communication-oriented teaching: where are we now? Where do we go from here?' Language Teaching, 47, 249-362.

Long, M. (1985). A role for instruction in second language acquisition: task-based language teaching. In K. Hyltenstam and M. Pienemann (eds.). Modelling and assessing second language acquisition (pp. 77-100). Clevedon: Multilingual Matters. 
Long, M. (1988). Instructed interlanguage development. In L. Beebe (Ed.). Issues in second language acquisition: multiple perspectives (pp. 115-141). Rowley, Mass: Newbury House).

Long, M. (2015). Second language acquisition and task-based language teaching. Malden, USA: Wiley-Blackwell.

Long, M. H. (2016). In defence of tasks and TBLT: nonissues and real issues. Annual Review of Applied Linguistics, 36, 5-33.

Loschky, L. \& R. Bley-Vroman. (1993). Grammar and task-based methodology. In G. Crookes \& S. Gass (Eds.), Tasks and language learning: integrating theory and practice (pp. 123-167). Clevedon: Multilingual Matters.

Lyster, R. (2004). Differential effects of prompts and recasts in form-focused instruction. Studies in Second Language Acquisition, 26(3), 399-432.

Mackey, A. (1999). Input, interaction and second language development: an empirical study of question formation in ESL'. Studies in Second Language Acquisition, 21, 557-87.

Mochizuki, N. \& Ortega, L. (2008). Balancing communication and grammar in beginninglevel foreign language classrooms: A study of guided planning and relativization. Language Teaching Research, 12, 11-37.

Nassaji, H., \& Fotos, S. (2007). Current issues in form-focused instruction. In S. Fotos \& H. Nassaji (Eds.), Form-focused instruction and teacher education: Studies in honour of Rod Ellis (pp. 7-15). Oxford: Oxford University Press.

Norris, J., and L. Ortega. (2000). Effectiveness of L2 instruction: a research synthesis and quantitative meta-analysis. Language Learning, 50, 417-528.

Philp, J. \& Duchesne, S. (2016). Exploring engagement in tasks in the language classroom. Annual Review of Applied Linguistics, 36, 50-72.

Pica, T. (2006). The essential role of negotiation in the communicative classroom. JALT Journal, 18, 241-268,

Pienemann, M. (1985). Learnability and syllabus construction. In K. Hyltenstam \& M. Pienemann (Eds.). Modelling and assessing second language acquisition (pp. 23-75). Clevedon: Multilingual Matters.

Prabhu, N.S. (1987). Second language pedagogy. Oxford: Oxford University Press.

Robinson, P. (2010). Task-based language teaching: a review of the issues. Language Learning, 61, 1-36.

Robinson, P. (2011). Second language task complexity, the Cognition Hypothesis, language learning, and performance. In Robinson P. (Ed.). Second language task complexity: 
researching the cognition hypothesis of language learning and performance (pp 338). Amsterdam: John Benjamins.

Sasayama, S. (2016). Is a 'complex' task really complex? Validating the assumption of task complexity. Modern Language Journal, 100 (1), 231-254.

Schmidt, R. (1990). The role of consciousness in second language learning. Applied Linguistics, 11, 129-158

Seedhouse, P. (1997). The case of the missing "no"; the relationship between pedagogy and interaction'. Language Learning, 47, 547-83.

Sheen, R. (1994). A critical analysis of the advocacy of the task-based syllabus. TESOL Quarterly, 28, 127-57.

Sheen, R. (2006). Focus on forms as a means of improving accurate oral production. In A. Housen and M. Pierrard (eds.). Investigations in instructed second language acquisition (pp. 271-310). Berlin: Mouton de Gruyter.

Shehadeh, A. (2005). Task-based learning and teaching: theories and applications. In C. Edwards \& L. Willis (Eds). Teachers exploring tasks (pp. 13-30). Basingstoke: Palgrave McMillan.

Shintani, N. (2016). Input-based tasks in foreign language instruction for young learners. Amsterdam, Netherlands: John Benjamins

Skehan, P. (1998). A cognitive approach to language learning. Oxford: Oxford University Press.

Soars, L. \& Soars, J. (2013). New headway. Oxford: Oxford University press.

Spada, N. (1987). Relationships between instructional differences and learning outcomes: a process-product study of communicative language teaching. Applied Linguistics 8, 2, $137-61$.

Swan, M. (2005). Legislating by hypothesis: the case of task-based instruction. Applied Linguistics, 26, 376-401.

Swan, M and Walter, C. (1984). The Cambridge English course. Cambridge; Cambridge University Press.

Van den Branden, K. (Ed.). (2006). Task-based language education: From theory to practice. Cambridge: Cambridge University Press.

White, R. (1988). The ELT curriculum, design, innovation and management. Oxford: Basil Blackwell.

Wilkins, D. (1976). Notional syllabuses. Oxford: Oxford University Press. 
Yalçin, S. \& Spada, N. Language aptitude and grammatical difficulty. Studies in Second Language Acquisition, 38, 239-263.

Yalden, J. (1983). The communicative syllabus: evolution, design and implementation. Oxford: Pergmaon.

Yalden, J. (1986). An interactive approach to syllabus design: the frameworks project. In C. Brumfit (Ed.). The practice of communicative teaching: EKT Documents 124 (pp. 2538). Oxford: Pergamon and the British Council. 